\title{
El secretario real Francisco Ramírez de Madrid. Apuntes para una biografía $^{1}$
}

\author{
Pedro A. Porras Arboledas*
}

Capitán general murió en Granada

a manos de los moros, cuya vida honró a Madrid, pero la más honrada

patria ¡cuán presto el sacrificio olvida! ${ }^{2}$

En la época de los Reyes Católicos se asiste a un notable aumento de la actividad administrativa, como resultado de su política de concentración de poderes y de extensión de sus atribuciones. Para la fundamentación del Estado Moderno ideado por estos monarcas hubieron de servirse de buen número de personas de probada fidelidad y de competencia conocida; buenos administradores, en suma. Al propio tiempo, debieron contar con el concurso de hombres experimentados en el arte de la guerra; hombres que les sirvieran en las numerosas campañas que hubieron de realizar, desde la guerra de sucesión contra la Beltraneja hasta la anexión del Reino de Navarra.

* Profesor Titular de Historia del Derecho. Universidad Complutense de Madrid.

1 El presente trabajo es un resumen de una biografía más amplia que hemos realizado de este personaje y de sus dos esposas, Isabel de Oviedo y, especialmente, Beatriz Galindo "La Latina", que será editado por la Comunidad Autónoma de Madrid a lo largo de 1996. Este extracto fue presentado como comunicación al Congreso Internacional de la Península lbérica en la «Era de los Grandes Descubrimientos", celebrado en Sevilla en 1991.

El archivo de la Casa de Bornos, de la que Francisco Ramirez fue creador, se encuentra en la sección de Diversos del Archivo Histórico Nacional de Madrid, cuyos fondos hemos inventariado en otro trabajo que aparece en este mismo número de ETF. En la redacción de estas páginas se ha utilizado un inventario de los papeles de Bornos realizado en torno a 1740 (AHN, Diversos, Títulos y familias, legajo 1.578).

2 Verso de la Jerusalem conquistada de Lope de Vega, citada por FÉLIX DE LLANOS Y TORRIGLIA (Una consejera de Estado, doña Beatriz Galindo "La Latina", Madrid, 1920, p. 37). Aparte de esta conferencia, un tanto limitada en sus objetivos, contamos con otra biografía de tono hagiográfico, debida a Cristina de Arteaga (Beatriz Galindo, «La Latina», Madrid, 1975). En el archivo de la Casa se conserva manuscrita otra breve biografia de la misma, escrita en 1721 por el presbítero CRISTÓbal Gómez dE LA VEga y MONTALVo. 
Precisamente en la conjunción de estos dos factores es donde radica el éxito de Francisco Ramírez: durante los 27 años que sirvió a los Reyes demostró una valía extraordinaria tanto en el campo de la administración como en el de la milicia; de ahí proviene su rápido encumbramiento y la notable acumulación de oficios y honores.

\section{ACTIVIDADES PÚBLICAS}

No es mucho lo que sabemos de sus orígenes familiares, ya que el archivo de la Casa guarda silencio sobre el asunto ${ }^{3}$; lo cierto es que Francisco Ramírez fue el segundogénito de Catalina Ramírez de Cóbreces y de Juan Ramírez de Oreña, montañeses de cuna - concretamente, de San Vicente de la Barquera ${ }^{4}$ - y afincados en Madrid, de donde Juan Ramírez fue regidor. El hecho de no ser Francisco el mayor de los hermanos explicaría esta ausencia de documentos paternos entre sus papeles.

Lo cierto es que Francisco Ramírez de Oreña, que cambiaría su apellido por el de Ramírez de Madrid en honor a su lugar de residencia - sus hermanos, Sancho de Oreña y Diego Gutiérrez de Oreña, no lo perderían ${ }^{5}$-, no consta documentalmente hasta los años finales del reinado de Enrique IV, en cuya Corte debió de educarse y crecer, merced a la influencia de su suegro, el escribano Juan Alfonso de Oviedo. En aquellas fechas to hallamos como criado del Rey, cuando el monarca le confirió los oficios de escribano y alcaide, respectivamente, de las cecas de Segovia y Toledo, y le otorgó un juro de $80.000 \mathrm{mrs}$., además de ciertos excusados, situados y salvados en las rentas de Madrid, Toledo, Sahagún y las salinas de Espartinas.

En la difícil transición del reinado de Enrique IV al de los Reyes Católicos Francisco Ramírez supo conservar su posición en la Corte, decantándose decididamente por el bando triunfante; pero fue en la batalla

No deja de llamar la atención que no se le halla dedicado ningún estudio a Francisco Ramírez, personaje tan relevante en la Corte de los Reyes Católicos.

3 Aparte de unas genealogías contradictorias conservadas en el legajo 1502, sólo se incluye un breve de Paulo II, fechado en 1464, concediendo facultad a los padres de Francisco para elegir confesor de pecados reservados. Se pueden encontrar diversos datos genealógicos en la obra del licenciado Gerónimo de Quintana (A la Muy Antigua, Noble y Coronada Villa de Madrid, Historia de su antigüedad, nobleza y grandeza, Madrid, 1629, vol. 2, pp. 255r-265v y 430v-407r).

4 Todavía en 1499, al testar Francisco Ramírez, dispuso que en los llamamientos de los mayorazgos de sus dos hijos sucediera en octavo lugar su primo Diego de Cóbreces, vecino de San Vicente de la Barquera.

5 Otra hermana, doña Isabel, mujer de Pedro de Victoria, es citada en los llamamientos de sus mayorazgos. 
de Zamora, donde Francisco Ramírez debió distinguirse notablemente a los ojos de los Reyes, quienes acto seguido le confirmaron las mercedes y oficios recibidos de su antecesor, nombrándole, además, en un momento indeterminado de 1476 —entre abril y agosto-secretario real. Durante la campaña contra el portugués intervendría organizando el apoyo logístico de las tropas a lo largo de la frontera, acumulando una experiencia que le sería de gran utilidad en los años siguientes. También en 1480 participará en la organización de una armada contra los turcos.

En los años que median entre la toma de Zamora y el inicio de la Guerra contra Granada nuestro personaje afianza decididamente su posición: para 1476 es recibido como miembro del Consejo; al año siguiente es nombrado regidor de Toledo y alcaide del Alcázar, Atarazanas y Puerta de Jerez de la Ciudad de Sevilla, en tanto que en 1481 es designado obrero mayor del mismo conjunto monumental en el que perduraría hasta $1495^{\circ}$-además de escribano de rentas de Madrid y, probablemente, también escribano de rentas del Maestrazgo de la Orden de Santiago. Así mismo, recibió sendos juros de 36.000 y $11.000 \mathrm{mrs}$. sobre las tercias de Madrid y las alcabalas de Toledo, respectivamente.

Sería, sin embargo, la Guerra de conquista del Reino de Granada ${ }^{7}$ la que daría a Francisco de Madrid ocasión de demostrar sus capacidades y le permitiría amasar un patrimonio nada desdeñable, sobre el que se establecerían dos mayorazgos, orígenes de los señoríos de Bornos y Rivas. La buena actuación durante la campaña de Zamora de don Francisco determinaría que los Reyes le nombrasen capitán general de su artillería durante toda aquella guerra ${ }^{8}$; de ahí el sobrenombre de «El Artillero» con el que se le conocería en adelante ${ }^{9}$.

- La rendición de cuentas por esta obrería fue efectuada en 11 de abril de 1498 , recibiendo finiquito en aquella fecha; este documento falta del legajo 2.415 de la Casa, pero una copia, donde se reseña su contabilidad entre 1481 y 1495, se halla en Simancas (Contaduría Mayor de Cuentas, $1^{\text {a }}$ época, legajo $1.483, \mathrm{n}^{\mathrm{0}} 1$ ).

7 Los datos de estas campañas tomados de Miguel A. LADERo: Castilla y la conquista del Reino de Granada. Valladolid, 1967.

\& En 1486 el Artillero recibiría $100.000 \mathrm{mrs}$. de ayuda de costa y dos años después otra cantidad similar por el cargo que tenía de la artillería, tomados de los 800.000 con que contribuia anualmente la Hermandad para el mantenimiento de ese cuerpo.

${ }^{\circ}$ El 13 de septiembre de 1493 , en Medina del Campo, rendiría don Francisco la cuenta final de los gastos de la artilleria durante la guerra; por desgracia este relevante documento - como tantos otros - ha desaparecido del legajo 2.415, donde se hallaba hasta épocas no muy lejanas. Sólo se pueden reconstruir los gastos (sueldos de carreteros y bueyes) efectuados por los de Jerez de la Frontera en el cerco y toma de Setenil (Archivo General de Simancas, Contaduría Mayor de Cuentas, $1^{\text {a }}$ época, leg. 87). 
A través de documentación fragmentaria, tomada de distintos archivos municipales (especialmente Sevilla, además de Carmona y Jaén), se pueden reconstruir las intensas actividades del Artillero a lo largo de toda la campaña granadina, actividades desarrolladas en dos sentidos: primero, organizando todo lo relativo a la convocatoria y desplazamiento del peonaje (pedreros, carpinteros, cavadores, hacheros, carreteros), bestias de carga, carretería y fardaje de la artillería, con todos los auxiliares encargados de allanar el camino para el paso de las piezas artilleras por lugares donde, en ocasiones, no había sendas transitables ${ }^{10}, y$, segundo, estudiando y fijando el emplazamiento de las piezas en los distintos asedios y utilizándolas.

Entre 1483 y 1489 documentamos un buen número de estos trabajos logísticos ${ }^{11}$, que tenían por base la Ciudad de Écija, donde se almacenaba la artillería, en una casa de su propiedad. Sin embargo, entre sus notables servicios en esta guerra destacan sus intervenciones en las expugnaciones de Cambil, Alhabar y Málaga y en la defensa de Salobreña.

Los castillos gemelos de Cambil y Alhabar serrian conquistados a fines de septiembre de 1485, tras ser cercados y bombardeados continuamente durante al menos dos días; Francisco Ramírez sería el responsable de esta conquista, ya que durante 12 dias anduvo al frente de 6.000 peones que fueron allanando el camino por una zona muy fragosa hasta depositar la artillería al pie mismo de estos castillos, dirigiendo poco después los tiros certeramente, de modo que a Mahomad Lentín, su alcaide, y a los gomeres que los defendían no les quedó más remedio que entregarlos ${ }^{12}$. En premio por

10 En la campaña de Cambil y Alhabar la Ciudad de Jaén hubo de suministrar buen número de peones cavadores, encargados de desbrozar y desmochar los montes para el paso de la artilleria, donde antes nunca jamás se pensó facer camino alguno, los cuales recibían la calificación de artilleros (PEDro A. Porras: "La sociedad de la Ciudad de Jaén a fines del siglo XV", En la España Medieval, III, 1982, pp. 310-318).

1 Durante estos años don Francisco debió utilizar en ocasiones métodos expeditivos, como nos lo indica el seguro dado por los Reyes, contra él, al escudero Juan de Ordax (AGS, Registro General del Sello, octubre de 1490, fol. 112), o el contencioso habido en Motril con la Reina Haja, viuda de Zaad, por los bienes que éste le retenía contra su voluntad (RGS, 13-febrero-1497, fol. 295).

12 Describe con detalle estas operaciones, sin citar a don Francisco, HeRnANDo DEL PULGAR, (Crónica de los señores Reyes Católicos, Madrid, 1953, pp. 427-429). Llama la atención que no lo cite en este lugar y sí posteriormente, ya que ambos, como se verá, mantuvieron estrechas relaciones durante la guerra. La cronologia de estos hechos no es totalmente clara, si se tiene en cuenta la costumbre de don Francisco de hacer una fundación religiosa con la advocación del día del asentamiento de la artillería (en el caso de Cambil el día 21, día de San Mateo).

Sobre estas operaciones existe una bonita monografía original de ALFREdo CAZABÁN (Jaén como base de la conquista de Granada, Jaén, 1904), donde se incluye el documento de donación de Bornos, en el que se relatan las actividades realizadas por el Artillero y los peones de Jaén. 
estos servicios los Reyes, el 2 de octubre del mismo año, le hicieron donación del cortijo de Bornos, situado en el término de Cambil, además de los bienes del antiguo alcaide Alí Cambili, con parte de los cuales fundó una capellanía bajo la advocación de San Mateo en la iglesia parroquial de esa aldea.

Igualmente penosa fue la marcha de la artillería castellana hasta el cerco de Vélez-Málaga ${ }^{13}$, no así la utilizada en Málaga, ya que fue transportada por mar; dos son los hechos de armas documentados por Pulgar en este asedio: el más inmediato fue la colocación de tiros de grueso calibre contra la fortaleza de Gibralfaro, pero el más sonado fue la conquista de una de las torres defensivas del puente sobre el Guadalmedina-luego conocido como de Santo Domingo-, que era el puente principal de acceso a la Ciudad por las barreras. La presencia personal del cronista permite la transmisión detallada de las operaciones: dicho puente de 4 ojos estaba protegido a ambos lados de sendas torres y fue preciso abrir una mina para colocar dentro, debajo de la de afuera, un cortago boca arriba, que abrió fuego en pleno combate, tras cuatro días de asedio, deshaciendo los suelos de la torre; de este modo el puente quedó inutilizado, pereciendo en el combate dos de los capitanes malagueños más notables, lo que, en palabras de Pulgar, fue causa que se ganase Málaga ${ }^{14}$.

Don Fernando, en agradecimiento por tan señalado servicio, armó caballero a don Francisco en esa misma torre el 4 de septiembre de 1487, en presencia de Hernando del Pulgar. Don Francisco, por su parte, atribuyendo el éxito de la operación a San Nuflo u Onofre, quien le habría inspirado en la ubicación de la artillería en esa ocasión, hizo erigir ese mismo año en tal lugar una ermita dedicada a ese santo, transformada más tarde en convento trinitario.

Probablemente el momento más apurado de su carrera militar lo pasó Francisco de Madrid en agosto de 1490, cuando Boabdil luego de tomar Alhendín marchó a Salobreña con idéntica intención, teniendo cercada la fortaleza durante 15 días; el ataque y la defensa fueron encarnizados, por lo áspero de las fortificaciones y el alto número de los asaltantes, que impedían la entrada de refuerzos. Don Francisco y sus hombres hubieron de proveerse por mar ${ }^{15}$, salvándole la noticia de la inminente

13 Tanto en el asedio de Vélez-Málaga como en los sitios de Loja y Moclín Francisco RamíREz utilizó el bombardeo de las «pelotas encendidas", es decir, el lanzamiento de proyectiles de fuego, que, además de incendiar inmuebles, causaban el desconcierto entre los asediados.

14 Ibidem, pp. 458 y $468-469$.

15 Se conservan varias cartas de pago y certificados del abasto que varios capitanes de naos de Almuñécar y Vélez-Málaga, que intervinieron en estos hechos, presentaron en 1501 a los testamentarios del secretario a fin de que se los hicieran afectivos. 
llegada del Rey Fernando por el Valle de Lecrín ${ }^{16}$. Éste, en reconocimiento, le nombró alcaide de Salobreña, con salario de $250.000 \mathrm{mrs}$., y mandó resarcirle por las pérdidas sufridas en sus bienes ubicados en Motril y Salobreña ${ }^{17}$.

Las recompensas recibidas por tan importantes servicios fueron notables: nombramiento de caballero en el arrabal malagueño, donación del cortijo jienense de Bornos y tenencia de Salobreña; pero, además, don Francisco consiguió importantes participaciones en los repartimientos de distintos lugares del Reino granadino, en especial en los territorios de la Ciudad de Almuñécar y, más concretamente, en Motril y Salobreña; asimismo, resultó heredado en Restábal, Deifontes, Zafayona, Málaga, Vélez-Málaga, Santa Fe, Montefrío, Alhendín y, por supuesto, en Granada ${ }^{18}$, donde, aparte de una participación en las rentas de los jelices de la Alcaicería, recibió unas casas junto al Zacatín, tomadas por los Reyes para la construcción de la Capilla Real, y otras también expropiadas por los monarcas para construir su Chancillería,

16 El 16 de agosto, estando el Rey en Córdoba, escribió a FRANCISCO DE MADRID encargándole que esforzase mucho a los de la fortaleza, mientras él acudía prestamente a socorrerlos.

17 ldem, pp. 508-509. Así relataban los Reyes los servicios militares prestados por don Francisco en carta de 1504, confirmatoria de la tenencia de Salobreña y salario correspondiente:

"... acatando los muchos e buenos, continuos, leales e señalados servicios que el dicho nuestro secretario nos hizo desde que por la gracia de Dios subcedimos en estos nuestros Reinos, asi en las guerras que tobimos con el Reino de Portugal e en la vatalla de Zamora fasta que la dicha guerra fue acabada, como después en la guerra e conquista de el dicho Reino de Granada, donde en todos los reales e cercos que nos tobimos sobre las ciudades e villas e lugares e fotalezas de el dicho Reino hasta que todo fue tomado e conquistado, estubo por nuestro mandado en el cargo de capitán de nuestra artillería, poniendo su persona a todo riesgo e peligro, especialmente quando teniendo la dicha villa e fortaleza de Salobreña cercada el Rey moro de Granada, e habiendo tomado la dicha villa e estando combatiendo muchos dias la dicha fotaleza, él en persona con mucha gente fue por la mar e se puso en el peñón que está dentro de la dicha mar, cerca de la dicha villa, e cada vez que el dicho Rey e moros de Granada combatian la dicha fortaleza, él con la gente que con él estaba, asi en el dicho peñón como en los dichos nabios salia a dar en el dicho real e gente de el dicho Rey e moros, a cuya causa cesaba el combate, e por el buen recaudo que en la dicha fortaleza él tobo se defendió fasta que yo el Rey entré poderosamente por la Vega de Granada, e el dicho Rey e moros alzaron el dicho cerco e fue socorrida la dicha fotaleza; e en el dicho cerco gastó muchas contias de mrs. e los dichos moros le robaron e tomaron, asi en la dicha villa de Salobreña como en la villa de Motril, muchos ganados e caballos e otras cosas de sus bienes; después de lo qual, al tiempo que los moros de la Serrania de Ronda se rebelaron contra nuestro servicio, el dicho Francisco de Madrid, nuestro secretario, fue por nuestro mandado por nos servir con cierta gente, junto con los cavalleros e capitanes que contra los dichos moros mandamos ir, a donde en el combate de la Sierra Bermeja fue muerto por los moros el dicho secretario..." (AHN, Diversos, Tyf, leg. 1.363).

${ }_{18}$ Los bienes radicados en Deifontes, Zafayona, Santa Fe, Alhendín y la huerta de la Puerta de Guadix en Granada serian enajenados, con licencia real, en 1529 por doña Teresa de Haro, viuda de don FERNANDO Ramirez, contra renta anual de $50.000 \mathrm{mrs}$. 
así como distintas tierras de cultivo junto al Darro y en la Puerta de Guadix ${ }^{19}$.

Durante los años que duró la guerra sus nombramientos para cargos y oficios no dejaron de aumentar; así, fue designado despensero mayor de raciones de la Casa Real ${ }^{20}$, regidor y escribano público de Madrid ${ }^{21}$, contador mayor de la Orden de Alcántara, escribano del crimen en las Ciudades de Málaga y Vélez-Málaga y obrero de los muros, torres y obras reales de Écija ${ }^{22}$. También del Vaticano consiguió varias mercedes, como la concesión de indulgencias por su participación en la guerra, otorgada por Sixto IV en 1483, y la autorización para usar altar portátil para celebrar misa en campaña, concedida por Inocencio VIII en 1488.

Terminada la guerra, Francisco de Madrid pudo ocuparse de poner orden en sus negocios, realizando importantes inversiones, como veremos más adelante. De hecho, entre 1494 y 1499 documentamos prolongadas estancias en Madrid, su lugar de residencia habitual ${ }^{23}$. No obstante, su tranquilidad no debió de ser total ya que durante buena parte del año 1496 anduvo el secretario aprestando la defensa de las localidades fronteras con el Reino de Navarra, en especial el lugar de Los Arcos.

En esta temporada de calma relativa don Francisco sólo aumentó su elenco personal de oficios con el nombramiento de despensero de la Casa del Príncipe don Juan ${ }^{24}$, si bien consiguió situar a su primogénito,

19 Durante este período sólo se documenta la concesión de un juro de $1.900 \mathrm{mrs}$. sobre la alcabala de la zapatería de Madrid a favor del secretario, fechada en el Real de Baza, el 17 de octubre de 1489. Su segunda esposa, Beatriz Galindo, realizó a la Reina un préstamo de guerra de $1.200 .000 \mathrm{mrs}$., que posteriormente le sería generosamente reembolsado.

20 En Simancas (Cámara de Castilla, Cédulas de la Cámara, libros 1 a 4) se conserva infinidad de actuaciones de don Francisco en el desempeño de este cargo hasta el momento mismo de su muerte. También en Obras y bosques (AmALIA PRIETo: Casa y descargos de los Reyes Católicos: Catálogo XXIV del Archivo Generai de Simancas, Valladolid, 1969).

21 La escribania de Madrid le fue concedida en un momento indeterminado, sin que llegara a ejercerla personalmente nunca; para 1500 la había cedido, y el concejo había consentido en ello, a su cuñado Gaspar de Gricio, como él secretario real.

22 En esta Ciudad, depositaria de la artillería durante las invernadas de la guerra, don Francisco consiguió un notable patrimonio, compuesto por varias casas, almazaras, aceñas, un cortijo y varios censos sobre predios rústicos. También en Carmona y en Córdoba, además de en Sevilla, logró reunir distintas fincas urbanas, como beneficiario de las confiscaciones a conversos y a partidarios del Rey de Portugal.

También los criados del secretario lograron beneficios de la conquista, como Fernando de Llerena, nombrado jurado de Ronda, en la collación de Santa María, tras su conquista (AGS, RGS, 12-mayo-1493, fol. 36).

${ }_{23}$ A través de sus asistencias a las reuniones del Cabildo municipal de Madrid y de las cartas que firmó como secretario y canciller real, hemos podido reconstruir mínimamente el itinerario de. Francisco de Madrid desde finales de 1476 hasta su fallecimiento.

24 En 1493 el concejo madrileño le había nombrado procurador para la Junta de Soria. 
Fernando Ramírez, como canciller de la Orden de Alcántara (1494), paje del Príncipe don Juan (1496) y montero mayor del Príncipe don Miguel (1499). Las atribuciones de juros a su familia son importantes en este período: en febrero de 1497 otorgan los Reyes a Beatriz Galindo uno de 100.000 mrs. sobre las alcabalas de Madrid; en mayo del mismo año esta señora recibe en precario las rentas del portazgo de Carrión y durante el año siguiente le recompensan su ayuda con el préstamo de guerra con sendos juros de 100.000 mrs. y 70.000 sobre las rentas de Madrid.

Apenas iniciado el siglo XVI don Francisco hallará la muerte en Sierra Bermeja el lunes día 18 de marzo de 1501, adonde había acudido por orden real a sofocar el levantamiento de los mudéjares de la Serranía de Ronda; allí quedó muerto el secretario junto con don Alonso de Aguilar y otros 80 hombres, entre escuderos y caballeros ${ }^{25}$.

Así fallecería el secretario Francisco de Madrid, del mismo modo en que había vivido y labrado su fortuna, guerreando al servicio de los Reyes Católicos; su muerte en plena actividad militar fue largamente recompensada por los monarcas: tan sólo una semana después de la muerte violenta de su padre la Reina Isabel prometía a Fernando Ramírez - que sólo contaba con ocho años y medio- otorgarle la tenencia de Salobreña, las escribanías de rentas de la Orden de Santiago y de Madrid, el oficio de despensero de sus raciones y la regiduría de Madrid, y a Nuflo Ramírez, su segundogénito, la contaduría mayor de Alcántara, las escribanías del crimen de Málaga ${ }^{26}$ y Vélez-Málaga y la escribanía de la ceca de Segovia; todo ello con condición de que Beatriz Galindo pudiese usar esos oficios hasta la mayoría de edad de sus dos hijos ${ }^{27}$.

La privanza de que gozaba La Latina cerca de la Reina Católica le permitirá consolidar la posición de sus hijos con una serie de generosas

25 Continuación de la Crónica de Pulgar, p. 551. Andrés Bernáldez, que no cita a Francisco de Madrid, sitúa este hecho luctuoso dos días antes (Historia de los Reyes Católicos don Fernando y doña Isabel, escrita por el bachiller..., Madrid, 1953, p. 697).

26 También ocupó el cargo de guarda mayor de la Mar, por el que cobraba un sustancioso derecho sobre las sacas de pan del puerto de Málaga; tras la muerte de Nuflo, a la vuelta de las bodas reales celebradas en Sevilla, se desató un complicado juego de intereses en torno a los oficios heredados de su padre en la capital maiagueña: por una parte, el concejo pretendía la consunción de la escribania del crimen, tal y como los Reyes les habían prometido, y, por otra, varios particulares, con importantes servicios prestados a la Corona en las campañas norteafricanas, pedían la atribución de la guarda mayor de la Mar (AGS, Cámara de Castilla. Memoriales, leg. 183, passim).

27 AGS, Cámara de Castilla. Memoriales, leg. 196, no 21. En 1529 La Latina solicitaba al Emperador confirmación de todos estos oficios, además de otros tres cargos para su hijo mayor, $80.000 \mathrm{mrs}$. vitalicios en recompensa por la alcaidía de EI Pardo, el hábito de Santiago con quitación en la Mesa Maestral y ración de $50.000 \mathrm{mrs}$. como contino real. 
concesiones, en las que, además de confirmarles los oficios paternos ${ }^{28}$, les condonará la mayor parte de los descubiertos dejados por don Francisco como despensero de la Casa Real y de la Casa de los Príncipes ${ }^{29}$; asímismo, el 5 de julio de 1502 los Reyes concederán la hidalguía a don Francisco y a toda su descendencia ${ }^{30}$.

\section{ACTIVIDADES PRIVADAS}

Se desconoce la fecha de nacimiento de Francisco de Madrid, pudiendo especularse con la posibilidad de que viniese al mundo en torno a 1445, pero sólo tenemos documentada su vida familiar a partir de 1473; en ese año se había desposado con la madrileña Isabel de Oviedo, hija - junto a Juan y Ana de Oviedo- de Juan Alfonso de Oviedo y Mari Álvarez de Hoz; el 5 de mayo de ese año le otorgaron carta dotal por valor de $80.000 \mathrm{mrs}$. sobre diversos predios en los alrededores de Madrid ${ }^{31}$. A la muerte de su suegro, en 1480, aún no le habían hecho efectiva la totalidad de la dote; Mari Alvarez fallecería en 1488 durante una epidemia de peste (hizo testamento porque el tienpo es peligroso e pestífero); su hija Isabel le había premuerto en diciembre de 1484 .

Los hijos del primer matrimonio de don Francisco fueron cinco: Juan Ramírez, alcaide de Peñafiel y, más tarde, jesuita, María de Oviedo, mujer del comendador Juan Gaitán, Catalina de Oviedo, casada en Écija con Antonio de Aguilar, Isabel de Oviedo, monja dominica en Sevilla, y Antonio de Oviedo, dominico en San Esteban de Salamanca.

28 Para 1510 ambos hermanos, aún menores de edad, fueron nombrados pajes de la Reina Juana; pero entre 1501 y 1504 FERNANDO RAMíREZ será nombrado comendador de Santiago, tras recibir el hábito, regidor de Madrid - con privilegio de rebaja de edad para servir el oficio-, aicaide de las fortalezas de El Pardo (Madrid), con salario de 100.000 mrs., y Salobreña y despensero mayor de raciones.

29 El 3 de junio de 1512 rendiría cuentas de las pagas de la Casa del Príncipe don Juan La Latina, como testamentaria de su difunto esposo.

El 16 de julio de 1502 los Reyes confirmaron a doña Beatriz y a sus hijos un juro de 14.700 mrs. sobre las rentas de Madrid, que, en realidad, no era más que la suma de otros tres procedentes de donaciones reales y de herencia paterna; poco antes la misma señora había comprado otro juro de $9.800 \mathrm{mrs}$. sobre las alcabalas de Trujillo.

Por un asiento del concejo madrileño sabemos que las rentas sobre las que tenían situados juros en ese partido procedían de las alcabalas de Borox y de las tercias de Pinto, Pozuelo, Mejorada, Torrebermeja, Daracalde, Biveros, Villanueva, Coslada y Fuencarral.

30. Archivo Municipal de Madrid, Libro horadado, fol. 434r-435r.

31 Incluían 6 tierras con una cabida total de 62 tanegas, sitas en la Mesa de Almarge, la Retamosa, las Jaboneras, Lavapiés, Santa María de Atocha y la Buitrera, además de una viña en Valderrama, de 3 aranzadas de mollar, y 2 fanegas de alcacer en Alvega. 
Durante estos años previos a la guerra de Granada Francisco Ramírez e Isabel de Oviedo constituyen un importante patrimonio en Madrid: como herederos de Juan Alfonso de Villamad o de Oviedo, escribano real, acumulan buen número de tierras y varias casas, adquiridas por éste entre 1438 y $1467^{32}$. La política de compras es continuada inteligentemente por nuestro personaje, amparándose en su ventajosa posición en la Corte: adquiere casas en San Ginés, Santiuste y Santa Cruz, además de un majuelo en el camino de Aravaca, si bien su interés se centró en conseguir un conjunto homogéneo de tierras cerca del casco urbano de Madrid; para ello fue acumulando lotes de huertas dentro de la Huerta de Atocha hasta celebrar en 1483 una permuta con el municipio, por la cual don Francisco consiguió la propiedad de las dos vertientes del arroyo de Atocha, que habían sido abrevadero comunal.

De este modo, constituyó una amplia propiedad que abarcaba desde lo que es hoy el Paseo del Prado hasta el final de la calle Delicias. La misma política siguió hasta conseguir controlar los molinos de Mohed, junto al Manzanares; en noviembre de 1481 compró varias ruedas de dichos molinos y obtuvo permiso de los otros propietarios para construir otra rueda, reparando él a su costa todas las instalaciones. Para 1497 adquiriría lo que le faltaba para redondear su dominio. Tal y como había sucedido con la Huerta de Atocha, Francisco Ramírez había reunido en sus manos todas las ruedas de estos molinos y el soto que los circundaba, es decir, toda la Pradera de San Isidro, como sería llamada más adelante, incluyendo las tierras sitas entre los puentes de Toledo y de Segovia. También pasaron a su propiedad los molinos de la Aldigüela, sitos en Pinto, que tenemos mal documentados.

Otro puntal de la excelente posición de don Francisco dentro de la pequeña villa de Madrid fue la capellanía de Atocha; esta había sido creada en 1466 por Diego Martinez de Zamora, secretario de Enrique IV, quien la cedió en 1480 a Francisco Ramírez; para ello le había situado 4.000 mrs. anuales en la martiniega madrileña, cedida a Zamora en 1465. Dicha capellanía permanecería en Santa Maria de Atocha hasta 1525 en que fue

32 Tierras situadas en Villaverde, Carabanchel, EI Pardo, Lavapiés, Huerta de Atocha, Almarge y camino del Puente de Segovia, más dos casas en San Ginés, en el arrabal, y otra en San Salvador, junto al domicilio marital.

Es de suponer que Villamad y Oviedo sean la misma persona, ya que sus esposas se llamaban del mismo modo y los documentos de ambos se conservan juntos; existe documentado entre 1468 y 1474 un secretario real de nombre Juan de Oviedo, con el que don Francisco mantuvo un contencioso por la capellanía de Atocha en 1496, siendo, por tanto, otra persona distinta. Ya en 1420 se documenta un Juan Díaz de Oviedo, secretario de Juan II. 
trasladada al Hospital de La Latina. Don Francisco aún crearía otra capellanía en Madrid en 1490: la de Santa Cruz, con licencia de Inocencio VIII.

Así pues, nuestro personaje se había convertido en el madrileño más importante de su época, lo que explica las contradictorias relaciones que mantuvo con su concejo, el cual le utilizó para influir en los asuntos que movía en la Corte ${ }^{33}$ y se enfrentó con él en múltiples ocasiones, llegándose siempre a acuerdos ventajosos para don Francisco; uno de ellos fue el de la Huerta de Atocha, otro fue el de las quejas por las represas hechas en el Manzanares, junto al soto de Mohed, saldado favorablemente para Francisco de Madrid por sentencia arbitral en 1498. Sin embargo, el asunto contencioso mejor documentado es el de la Alhóndiga del pan, que se extendió entre 1487 y 1498.

Alegaba el secretario que dicha casa le pertenecía como propietario del portazgo de Madrid —comprado previamente al conde de Alba de Liste-; el concejo pretendía que formaba parte de sus inalienables propios; se llegó finalmente al acuerdo de repartirse gastos e ingresos a partes iguales, debiendo gestionar aquél la supresión de la alcabala de la harina para la Alhóndiga.

Durante la guerra de Granada le llega la oportunidad a don Francisco de aumentar considerablemente sus bienes - al final de la contienda éstos se valoraban en 10.000 florines-, gracias a sus servicios; ya hemos considerado antes los beneficios obtenidos en los repartimientos de gran número de lugares del Reino de Granada, además del cortijo gienense de Bornos y el aumento de su patrimonio en Écija, su centro de operaciones. Pero donde demostró un mayor interés fue en Motril, donde continuó su política de concentración de propiedades, ya ensayada con éxito en Madrid. Para ello en los años inmediatos a la conquista de esa villa, don Francisco diputó permanentemente a un mayordomo que compró de judíos y musulmanes un importante número de tierras -fadines de huerta- y casas, además de las Salinas de Trafalcací. Así, el secretario se constituyó como el propietario predominante de Motril, posición en la que continuaron sus sucesores hasta principios del presente siglo ${ }^{34}$.

Enviudado a fines de 1484 don Francisco volvería a contraer nupcias a fines de febrero de 1491; por deseo de la Reina Isabel, éste desposó con

33 En esa política le sucedió su cuñado, el secretario Gaspar de Gricio, hermano de Beatriz Galindo, persona mucho más proclive a zascandilear en la Corte, como demostraría sobradamente. En esto se aprecia una gran diferencia entre las personas y las épocas.

34 He reunido la totalidad de estas cartas en mi artículo «Documentos sobre judíos y musulmanes en archivos señoriales y de protocolos", Cuadernos de Estudios Medievales y Ciencias y Técnicas Historiográficas, XVI, 1991. pp. 127-157. 
Beatriz Galindo, su maestra de latines, el día 26 en Sevilla. En esa fecha recibió de manos de la Reina medio millón de maravedies como dote de doña Beatriz Galindo, hija del difunto comendador Juan López de Gricio, vecino de Salamanca. Don Francisco le prometió en arras el diezmo de su fortuna, esto es, mil florines, por su crianza, linaje y virginidad ${ }^{35}$. El casamiento debió producirse el 20 de diciembre de 1491, estando en el Real sobre Granada, ya que en esa fecha la Reina hizo merced a doña Beatriz de 400.000 mrs., una cuarta parte para vestuario y el resto para ayuda de casamiento ${ }^{36}$.

Nacería el hijo primogénito de ambos la noche de San Bartolomé de 1492 (24 de agosto), siendo amamantado durante 3 años por la mujer de Mateo de Torquemada; éste atestiguaría esto años después para fijar la edad exacta de Fernando Ramírez. Otro testigo fue aún más explícito: Juan de Castellar, también vecino de Madrid, declaró saber que había nacido el año que se ganó Granada porque fue a dar las badajadas a la campana de Santiuste quando Veatriz Galindo estaba de parto del dicho comendador.

No parece que este personaje fundara mayorazgo para los hijos de su primer matrimonio, pero sí lo hizo con don Fernando y don Nuflo, hijos de Beatriz Galindo. Tras obtener licencia real para hacerlo en mayo de 1499, don Francisco fundó sendos mayorazgos con ocasión de su testamento postrero (Madrid. 13 de octubre de 1499). El mayorazgo del comendador don Fernando Ramírez Galindo incluía los bienes de Madrid (casas de Santa Cruz, portazgo, Huerta de Atocha, molinos y soto de Mohed, molinos de Aldigüela y juro de $100.000 \mathrm{mrs}$. en las alcabalas y tercias de Madrid), Jaén (el cortijo de Bornos) y Granada (bienes en Granada, Motril, Salobreña y Deifontes).

Nuflo Ramírez conseguiría un mayorazgo menos valioso ${ }^{37}$, ya que incluía todas las propiedades situadas en Écija, además de los heredamientos obtenidos en Málaga y Montefrío. La notoria injusticia cometida

35 Mantenía, así mismo, la mejoría a su hijo Juan Ramírez en las tierras de Toledo; prometía mejorar en el tercio y quinto a los hijos que tuviese con doña Beatriz, si fuesen varones, en sus heredades al sur de Sierra Morena; si tuviese hijas sólo las mejoraría y si él la premuriere, le dejaría renta anual de $50.000 \mathrm{mrs}$.

36 En 1497 la Reina le asignaría otros 100.000 para ayuda de costa; el 8 de febrero de 1501 , estando en Granada doña Isabel y La Latina, aquélla dejó bien claro que el cuento de mrs. que le habia donado lo había sido en concepto de dote; iba firmada la carta por Gaspar de Gricio. Sin duda, se debían barruntar el peligro de las operaciones en que don Francisco se hallaba implicado y empezaban a prepararse para la sucesión frente a los hijos de su primer matrimonio.

${ }_{37}$ La documentación perteneciente a este mayorazgo la conocemos mucho peor debido a que el archivo de la Casa de Rivas, que se hallaba en el convento de Rivas de Jarama, debió perderse durante la última guerra civil. 
por su padre y el mal comportamiento demostrado por don Fernando -reiteradas desóbediencias a su madre, espíritu derrochador, etc.- moverán a La Latina a alterar la última voluntad de su difunto esposo, sólo unos meses después de su muerte. Así, en febrero de 1504 conseguirá de los Reyes nueva licencia para alterar los mayorazgos, lo que efectuó dos meses después; en los mismos elevó los bienes vinculados a favor de su segundo hijo y, conocedora de la experiencia anterior, fijó con todo detalle la identidad de los bienes en ambos mayorazgos ${ }^{38}$.

Doña Beatriz sobreviviría a su único marido más de treinta años, viendo también la muerte de sus dos hijos. Fallecería el 9 de noviembre de 1534 en su Hospital. Durante todos esos años, además de criar y formar a sus hijos, doña Beatriz se entregaría a la realización de obras pías, fundando dos conventos de la Concepción en Madrid (de jerónimas y franciscanas); pero su obra más señera fue la fundación del Hospital de la Concepción, que pronto sería conocido como el de La Latina, que acabaría dando nombre a un populoso distrito madrileño. Ese hospital, hoy tristemente desaparecido gracias la incuria de los munícipes de primeros de este siglo - su portada se conserva en la explanada de la Escuela de Arquitectura de Madrid-, fue erigido a partir de 1499 por expreso deseo testamentario de don Francisco y continuado pacientemente por su esposa, entrando en funcionamiento en la segunda década del siglo XVI, dando acogida a un exiguo número de enfermos pobres y con posibilidades de curación.

Allí pasó La Latina sus últimos años de vida y allí, por paradojas del destino, reposaría en 1599 doña María de Granada, descendiente de Boabdil, acuciada por problemas económicos:

"Y yo biéndome aora sola, y no con estado para poder andar en casas alquiladas, me metí en un cuarto del Espital de La Latina, a donde aora estoy" ${ }^{39}$.

38 El testamento de don Francisco es muy conocido y ha persistido en numerosas copias; de hecho es el testamento más antiguo conservado en el Archivo Histórico de Protocolos de Madrid (protocolo 314, fol. 709); en el Histórico Nacional quedan copias abundantes, como la de Consejos (leg. 37.82, n² 6.282) o las de la Casa (leg. 1.933, 1.537, etc.). p. 217.

39 Agustín Millares Carló: Contribuciones documentales a la historia de Madrid, Madrid, 1971 , 